\title{
Human platelet antigen-3 polymorphism as a risk factor for rheumatological manifestations in hepatitis $\mathbf{C}$
}

\author{
Natália Bronzatto Medolago $[1]$, Adriana Camargo Ferrasi ${ }^{[1]}$, Oswaldo Melo da Rocha ${ }^{[1]}$, \\ Maria Inês de Moura Campos Pardini ${ }^{[1]}$, Rejane Maria Tommasini Grotto ${ }^{[2]}$, \\ Aline Faria Galvani ${ }^{[1]}$ and Giovanni Faria Silva ${ }^{[1]}$
}

\begin{abstract}
[1]. Universidade Estadual Paulista, Departamento de Clínica Médica, Faculdade de Medicina de Botucatu, Botucatu, SP, Brasil.
[2]. Universidade Estadual Paulista, Departamento de Bioprocessos e Biotecnologia, Faculdade de Ciências Agronômicas, Botucatu, SP, Brasil.
\end{abstract}

\begin{abstract}
Introduction: Hepatitis $\mathrm{C}$ virus $(\mathrm{HCV})$ infection is involved in the pathogenesis of autoimmune and rheumatic disorders. Although the human platelet antigens (HPA) polymorphism are associated with HCV persistence, they have not been investigated in rheumatological manifestations (RM). This study focused on verifying associations between allele and genotype HPA and RM in patients with chronic hepatitis C. Methods: Patients (159) with chronic hepatitis C of both genders were analyzed. Results: Women showed association between HPA-3 polymorphisms and RM. Conclusions: An unprecedented strong association between rheumatological manifestations and HPA-3 polymorphism, possibly predisposing women to complications during the disease course, was observed.
\end{abstract}

Keywords: Hepatitis C. Human platelet antigens. Polymorphism. Rheumatological manifestations.

Chronic hepatitis $\mathrm{C}$ virus (HCV) infection is a worldwide public health problem with a global prevalence of $2-3 \%{ }^{1}$. In addition to being a frequent cause of chronic liver diseases such as hepatitis, cirrhosis, and hepatocellular carcinoma, it is also involved in the pathogenesis of various autoimmune and rheumatic disorders such as arthritis, vasculitis, sicca syndrome, porphyria cutanea tarda, lichen planus, nephropathies, thyroid diseases, lung fibrosis, among others ${ }^{1,2,3}$. Even though the rheumatic disorders are common among the extrahepatic manifestations, the mechanisms involved in the onset of these symptoms as well as the associated genetic factors are yet to be understood completely.

Host genetic factors such as the the human platelet antigens (HPA) polymorphism are also known to be associated with the infection and persistence of $\mathrm{HCV}^{4,5}$. However, there is no evidence of its relation to rheumatological manifestations.

HPAs result from the polymorphisms in the genes encoding surface glycoproteins of platelets, endothelial cells, and fibroblasts ${ }^{6,7}$, and are commonly involved in rheumatological

\footnotetext{
Corresponding author: Dra. Adriana Camargo Ferrasi.

e-mail: adriana.ferrasi@unesp.br

(D) 0000-0001-9200-5391

Received 28 April 2019

Accepted 3 October 2019
}

diseases. Considering that the fibroblasts express HPA, these proteins could be involved in rheumatological manifestations. Thus, the aim of this study was to verify associations between allele and genotype HPA-1, -3 , and -5 polymorphisms and rheumatological manifestations in patients with chronic hepatitis $\mathrm{C}$.

A total of 159 individuals aged between 18 and 80 years, of both genders and affected by chronic hepatitis $\mathrm{C}$, assisted at the Viral Hepatitis Outpatient Clinic of Botucatu Medical School, Unesp, Brazil, were included in this study. We only considered detectable HCV-RNA cases, with identification of HCV genotype, no previous hepatitis $\mathrm{C}$ treatment (naïve patients), with known fibrosis stage or clinical diagnosis of cirrhosis by image. Patients with HBV/HIV co-infection, chronic renal insufficiency, liver or renal transplantation, liver diseases, and other diffuse connective tissue diseases, including rheumatoid arthritis, according to Rheumatoid Arthritis Classification Criteria (ACR-EULAR 2010), were excluded ${ }^{8}$.

Clinical symptoms, such as presence of paresthesia sensations, Raynaud's phenomenon, cutaneous alterations, subcutaneous nodule, myalgia, muscle weakness, non-mechanical low back pain, arthralgia, arthritis, and other rheumatological manifestations were considered as rheumatological manifestations in this study. Laboratorial parameters evaluated were rheumatoid factor (qualitative and semi-quantitative) and anti-CCP (semi-quantitative) using Reumalatex kit (Labtest Diagnostica S/A, Lagoa Santa, MG, 
Brazil) and QUANTA LiteTM CCP3.1 kit (INOVA Diagnostic Inc., San Diego, CA, USA), respectively, according to the manufacturer's instructions.

Deoxyribonucleic acid (DNA) was isolated from the total blood using the Wizard ${ }^{\circledR}$ Minipreps DNA Purification System and used to genotype HPA-1 and HPA-3 with polymerase chain reaction-sequencespecific primers (PCR-SSP), as described by Klüter et al ${ }^{9}$. HPA-5 was genotyped using polymerase chain reaction-restriction fragment length polymorphism (PCR-RFLP), as described by Kalb et al ${ }^{10}$.

The association analysis between the categorical variables was performed using the $\chi^{2}$ or Fisher's exact test. Student's t-test was used for comparing the mean ages. Logistic regression was used to categorize the risk of the association among the groups. Odds ratio values with $95 \%$ confidence interval were also calculated. $P \leq 0.05$ was considered statistically significant.

This study was approved by the Ethics Committee on Research of Sao Paulo State University (Protocol 3727/2010), and conforms to the provisions of Helsinki Declaration of 1964, as revised in $1975,1983,1989,1996$, and 2000. All the participants of this study signed the individually informed consent forms.

Out of 159 individuals, 87 (54.7\%) were men and 72 (45.3\%) were women. The median and mean ages were 49 years ( 24 to 76 years) and 48.7 years, respectively.

Rheumatological manifestations were present in $72.3 \%$ of the patients. Table 1 shows the demographic and clinical characteristics related to rheumatic involvement. An association between female gender and development of rheumatological manifestations $(P=0.0201)$ was observed. This association was maintained when the data was subjected to multivariate logistic regression analysis $(P=0.0381)$. It is well-known that the rheumatic diseases are more prevalent in women, regardless of other concomitant clinical conditions ${ }^{11}$. The correlation between rheumatic manifestation and female gender was already observed in a research conducted with Egyptian population affected by chronic hepatitis $\mathrm{C}^{12}$. In addition,
Cacoub et a ${ }^{13}$ showed that more than $70 \%$ of the HCV-infected patients showed extrahepatic manifestations involving primarily joints, muscles, and skin, which as per our findings, were also associated to female gender.

Genotype and allele frequencies of HPA-1, -3 , and -5 were distributed according to the presence or absence of rheumatological manifestations. There was no significant association observed among the patients. However, upon considering the gender (Tables $\mathbf{2}$ and $\mathbf{3}$ ), the females showed a significant association between rheumatological manifestation and allele HPA-3a $(\mathrm{OR}=3.83,95 \% \mathrm{CI}=1.60-9.22$, and $P=0.0044)$ and HPA-3a3a $(\mathrm{OR}=6.98,95 \% \mathrm{CI}=1.42-34.31$, and $P=0.0125$ ). Moreover, a risk was also observed for HPA-1a1b $(\mathrm{OR}=7.67,95 \% \mathrm{CI}=0.93-63.02$, and $P=0.0482)$. On the contrary, HPA-3b3b was protective $(\mathrm{OR}=0.21,95 \% \mathrm{CI}=0.47-0.93$, and $P=0.0496)$ for rheumatological manifestations.

In this context, it is noteworthy that HPA- 1 and HPA-3 are located in the same glycoprotein complex (GPIIb-IIIa) expressed in both endothelial cells and fibroblasts ${ }^{7}$, which are the cells commonly involved in rheumatological diseases. However, additional studies involving other populations are necessary to confirm these data and to improve the understanding of the mechanisms involved in rheumatic manifestations in chronic HCV infection. Similar to the well-established association of human leukocyte antigens (HLA) and diseases, studies involving HPA may also contribute towards the identification of clinically important molecular markers, thereby aiding in understanding the pathophysiological mechanisms involved in the diseases.

Our study is the first report of a strong association between rheumatological manifestations and HPA-3 polymorphism, which may explain the possible predisposition of women to complications during the course of chronic hepatitis $\mathrm{C}$.

\section{ACKNOWLEDGMENTS}

We would like to thank all the patients who participated in the study and all the employees of the institution, who in some way, collaborated with the execution of the research.

TABLE 1: Clinical and demographic characteristics of the population with chronic hepatitis C, distributed by presence or absence of rheumatological manifestations.

\begin{tabular}{|c|c|c|c|}
\hline Variables & $\begin{array}{c}\text { Presence of rheumatological } \\
\text { manifestations } \\
n=115(\%)\end{array}$ & $\begin{array}{l}\text { Absence of rheumatological } \\
\text { manifestations } \\
n=44(\%)\end{array}$ & $P$-value \\
\hline Age (years), mean & $49.6 \pm 10.0$ & $46.3 \pm 10.3$ & $0.0672^{\dagger}$ \\
\hline \multicolumn{4}{|l|}{ Sex } \\
\hline Male & $56(64.4)$ & $31(35.6)$ & \multirow{2}{*}{0.0201} \\
\hline Female & $59(81.9)$ & $13(18.1)$ & \\
\hline \multicolumn{4}{|l|}{ Ethnicity } \\
\hline White & $102(72.3)$ & $39(27.7)$ & \multirow{2}{*}{1.0000} \\
\hline Non-white & $13(72.2)$ & $5(27.8)$ & \\
\hline \multicolumn{4}{|l|}{ HCV Genotype } \\
\hline 1 & $80(73.4)$ & $29(26.6)$ & \multirow{2}{*}{0.7042} \\
\hline Not 1 & $35(70.0)$ & $15(30.0)$ & \\
\hline \multicolumn{4}{|l|}{ Fibrosis $^{\ddagger}$} \\
\hline Absent (F0) & $3(75.0)$ & $1(25.0)$ & \multirow{4}{*}{0.0519} \\
\hline Moderate (F1, F2) & $48(64.0)$ & $27(36.0)$ & \\
\hline Advanced (F3) & $20(69.0$ & $9(31.0)$ & \\
\hline Cirrhosis & $44(86.3)$ & $7(13.7)$ & \\
\hline
\end{tabular}

Fisher's exact test or Chi-square test $\left(\mathbf{X}^{2}\right) ; P \leq 0.05$ is considered a statistically significant relation; ${ }^{\dagger} \mathrm{T}$-test; ${ }^{\ddagger}$ Histological grouping. 
TABLE 2: Genotype and allele frequencies of HPA-1, -3 , and -5 in women with chronic hepatitis $C$, distributed by the presence and absence of rheumatological manifestations.

\begin{tabular}{|c|c|c|c|c|}
\hline HPA & $\begin{array}{l}\text { Presence of } \\
\text { rheumatological }\end{array}$ & $\begin{array}{l}\text { Absence of } \\
\text { rheumatological }\end{array}$ & \multicolumn{2}{|c|}{ Statistical Analysis } \\
\hline Alleles & $2 n=118(\%)$ & $2 n=26(\%)$ & OR (Cl 95\%) & P-value \\
\hline $1 \mathrm{a}$ & $93(80.2)$ & $23(19.8)$ & $0.49(0.13-1.75)$ & \multirow{2}{*}{0.4111} \\
\hline $1 \mathrm{~b}$ & $25(89.3)$ & $3(10.7)$ & $2.06(0.57-7.43)$ & \\
\hline 3a & $87(88.8)$ & $11(11.2)$ & $3.83(1.60-9.22)$ & \multirow{2}{*}{0.0044} \\
\hline $3 b$ & $31(67.4)$ & $15(32.6)$ & $0.26(0.11-0.63)$ & \\
\hline $5 a$ & $99(79.8)$ & $25(20.2)$ & $0.21(0.03-1.63)$ & \multirow{2}{*}{0.1257} \\
\hline $5 b$ & $19(95.0)$ & $1(5.0)$ & $4.80(0.61-37.60)$ & \\
\hline Genotypes & $\mathrm{n}=58(\%)$ & $n=13(\%)$ & OR (CI 95\%) & $P$-value \\
\hline $1 a / 1 a$ & $35(76.0)$ & $11(24.0)$ & $0.27(0.05-1.31)$ & 0.1155 \\
\hline $1 a / 1 b$ & $23(95.8)$ & $1(4.2)$ & $7.67(0.93-63.02)$ & 0.0482 \\
\hline $1 b / 1 b$ & $1(50.0)$ & $1(50.0)$ & $0.21(0.01-3.55)$ & 0.3306 \\
\hline $3 a / 3 a$ & $33(94.3)$ & $2(5.7)$ & $6.98(1.42-34.31)$ & 0.0125 \\
\hline $3 a / 3 b$ & $21(75.0)$ & $7(25.0)$ & $0.47(0.14-1.60)$ & 0.3460 \\
\hline $3 b / 3 b$ & $5(55.6)$ & $4(44.4)$ & $0.21(0.47-0.93)$ & 0.0496 \\
\hline $5 a / 5 a$ & $42(77.8)$ & $12(22.2)$ & $0.21(0.03-1.71)$ & 0.1628 \\
\hline $5 a / 5 b$ & $15(93.8)$ & $1(6.2)$ & $4.09(0.49-34.20)$ & 0.2723 \\
\hline $5 b / 5 b$ & $2(100.0)$ & $0(0)$ & $1.17(0.05-25.91)$ & 1.0000 \\
\hline
\end{tabular}

Fisher's exact test; OR: odds ratio; $\mathbf{C l}$ : confidence interval; $P \leq 0.05$ is considered a statistically significant relation.

TABLE 3: Genotype and allele frequencies of HPA-1, -3 , and -5 in men with chronic hepatitis $C$, distributed by the presence and absence of rheumatological manifestations.

\begin{tabular}{|c|c|c|c|c|}
\hline HPA & $\begin{array}{l}\text { Presence of } \\
\text { rheumatological }\end{array}$ & $\begin{array}{c}\text { Absence of rheumatological } \\
\text { manifestations }\end{array}$ & \multicolumn{2}{|c|}{ Statistical Analysis } \\
\hline Alleles & $2 n=112(\%)$ & $2 n=62(\%)$ & OR (CI 95\%) & $P$-value \\
\hline $1 a$ & $97(66.4)$ & $49(33.6)$ & $1.72(0.76-3.90)$ & \multirow{2}{*}{0.2030} \\
\hline $1 \mathrm{~b}$ & $15(53.6)$ & $13(46.4)$ & $0.58(0.26-1.32)$ & \\
\hline 3a & $76(62.8)$ & $45(37.2)$ & $0.80(0.40-1.58)$ & \multirow{2}{*}{0.6067} \\
\hline $3 b$ & $36(67.9)$ & $17(32.1)$ & $1.25(0.63-2.50)$ & \\
\hline $5 a$ & $99(64.7)$ & $54(35.3)$ & $1.13(0.44-2.89)$ & \multirow{2}{*}{0.8115} \\
\hline $5 b$ & $13(61.9)$ & $8(38.1)$ & $0.89(0.35-2.27)$ & \\
\hline Genotypes & $n=56(\%)$ & $\mathrm{n}=31(\%)$ & OR (Cl 95\%) & $P$-value \\
\hline $1 \mathrm{a} / 1 \mathrm{a}$ & $44(69.8)$ & $19(30.2)$ & $2.32(0.88-6.08)$ & 0.1318 \\
\hline $1 a / 1 b$ & $9(45.0)$ & $11(55.0)$ & $0.35(0.13-0.97)$ & 0.0612 \\
\hline $1 b / 1 b$ & $3(75.0)$ & $1(25.0)$ & $1.70(0.17-17.07)$ & 1.0000 \\
\hline $3 a / 3 a$ & $26(63.4)$ & $15(36.6)$ & $0.92(0.38-2.23)$ & 1.0000 \\
\hline $3 a / 3 b$ & $24(61.5)$ & $15(38.5)$ & $0.80(0.33-1.93)$ & 0.6577 \\
\hline $3 b / 3 b$ & $6(85.7)$ & $1(14.3)$ & $3.60(0.41-31.39)$ & 0.4135 \\
\hline $5 a / 5 a$ & $44(65.7)$ & $23(34.3)$ & $1.28(0.46-3.56)$ & 0.7908 \\
\hline $5 a / 5 b$ & $11(57.9)$ & $8(42.1)$ & $0.70(0.25-1.99)$ & 0.5907 \\
\hline $5 b / 5 b$ & $1(100.0)$ & $0(0)$ & $1.70(0.07-43.09)$ & 1.0000 \\
\hline
\end{tabular}

Fisher's exact test; OR: odds ratio; $\mathrm{Cl}$ : confidence interval; $P \leq 0.05$ is considered a statistically significant relation. 


\section{AUTHORS' CONTRIBUTION}

NBM: designed the study, performed procedures, acquisition/ analysis of data and writing the manuscript; ACF: designed the study, performed procedures, acquisition/analysis of data and writing the manuscript; OMR: designed the study, performed procedures, acquisition and analysis of data; MIMCP: contributed to design the study, performed procedures and acquisition of data; RMTG: contributed to design the study, performed procedures and acquisition of data; AFG: performed procedures and acquisition of data; GFS: drafted study concept and design, critical revision of the manuscript and study supervision.

\section{CONFLICTS OF INTEREST}

The authors declare no conflicts of interest with respect to the authorship and publication of this article.

\section{FINANCIAL SUPPORT}

This work was supported by the grant from São Paulo Research Foundation - FAPESP (grant number 2011/22049-6).

\section{REFERENCES}

1. Antonelli A, Ferri C, Galeazzi M, Giannitti C, Manno D, Mieli-Vergani $\mathrm{G}$, et al. HCV infection: pathogenesis, clinical manifestations and therapy. Clin Exp Rheumatol. 2008; 26(1 Suppl 48):39-47.

2. Ferri C, Ramos-Casals M, Zignego AL, Arcaini L, Roccatello D, Antonelli A, et. al. International diagnostic guidelines for patients with HCV-related extrahepatic manifestations. A multidisciplinary expert statement. Autoimmun Rev. 2016;15(12):1145-60.

3. Palazzi C, D'Angelo S, Olivieri I. Hepatitis C virus-related arthritis. Autoimmun Rev. 2008;8(1):48-51.
4. Bierling P, Pignon JM, Kuentz M, Mitjavila MT, Fromont P, Barbu V, et al. Thrombocytopenia after bone marrow transplantation caused by a recipient origin $\mathrm{Br}(\mathrm{a})$ allo-antibody: presence of mixed chimerism 3 years after the graft without hematologic relapse. Blood. 1994;83(1):274-9.

5. Verdichio-Moraes CF, Toralles-Pereira C, Grotto RMT, Silva GF, Pardini MIMC. Allelic frequencies of HPA-1 to 5 human platelet antigens in patients infected with hepatitis C virus. J Med Virol. 2009;81(4):757-9.

6. Curtis BR, McFarland JG. Human platelet antigens-2013. Vox Sang 2014;106:93-102.

7. Giltay JC, Brinkman HJ, von dem Borne AE, van Mourik JA. Expression of the alloantigen Zwa (or P1A1) on human vascular smooth muscle cells and foreskin fibroblasts: a study on normal individuals and a patient with Glanzmann's thrombasthenia. Blood. 1989;74(3):965-70.

8. Aletaha D, Neogi T, Silman AJ, Funovits J, Felson DT, Bingham CO 3rd. 2010 rheumatoid arthritis classification criteria: an American College of Rheumatology/European League Against Rheumatism collaborative initiative. Ann Rheum Dis. 2010;69(9):1580-8.

9. Klüter H, Fehlau K, Panzer S. Rapid typing for human platelet antigen systems $-1,-2,-3$ and -5 by PCR amplification with sequence-specific primers. Vox Sang. 1996;71:121-5.

10. Kalb R, Santoso S, Unkelbach K, Kiefel V, Mueller-Eckhardt C. Localization of the $\mathrm{Br}$ polymorphism on a $144 \mathrm{bp}$ exon of the GPIa gene and its application for platelet DNA typing. Tromb Haemost. 1994;71(5):651-4.

11. Talsania M, Scofield RH. Menopause and Rheumatic Disease. Rheum Dis Clin North Am. 2017;43(2):287-302.

12. Mohammed RHA, ElMakhzangy HI, Gamal A, Mekky F, El Kassas $\mathrm{M}$, Mohammed N, et al. Prevalence of rheumatologic manifestations of chronic hepatitis $\mathrm{C}$ virus infection among Egyptians. Clin Rheumatol. 2010;29(12):1373-80.

13. Cacoub P, Poynard T, Ghillani P, Charlott F, Olivi M, Piette JC, et al. Extrahepatic manifestations of chronic hepatitis C. MULTIVIRC Group. Multidepartment Virus C. Arthritis Rheum. 1999;42(10):2204-12. 